\title{
Mutation Spectra of BRCA Genes in Iranian Women with Early Onset Breast Cancer - 15 Years Experience
}

\author{
Vahid Reza Yassaee ${ }^{1,2 *}$, Zeinab Ravesh ${ }^{1}$, Ziba Soltani ${ }^{1}$, Feyzollah Hashemi-Gorji ${ }^{1}$, \\ Seyed Mohammad Poorhosseini ${ }^{2}$, Robab Anbiaee ${ }^{3}$, Azadeh Joulaee ${ }^{4}$
}

\begin{abstract}
Breast cancer is the most common cancer in Iran. In the recent years an upward trend has been observed in the Iranian population. Early detection by molecular approaches may reduce breast cancer morbidity and mortality. We provided consultation to 3,782 women diagnosed with early onset breast cancer during the past 15 years (1999-2014). To establish a data set for BRCA gene alterations of the Iranian families at risk, two hundred and fifty four women who met our criteria were analyzed. A total number of 46 alterations including 18 variants with unknown clinical significance (39.1\%), 18 missense mutations (39.1\%), 7 Indels (15.2\%) and 3 large rearrangement sequences $(6 \%)$ were identified. Further scanning of affected families revealed that $49 \%$ of healthy relatives harbor identical causative mutations. This is the first report of comprehensive BRCA analysis in Iranian women with early onset breast cancer. Our findings provide valuable molecular data to support physicians as well as patients for the best decision making on disease management.
\end{abstract}

Keywords: Breast cancer - BRCA1 - BRCA2 - genetic testing - mutation - disease management

Asian Pac J Cancer Prev, 17, Cancer Control in Western Asia Special Issue, 149-153

\section{Introduction}

Breast cancer is the most frequent invasive cancer comprising $16 \%$ of all cancers in women in both developed and under developed countries. Being a woman is an enormous contributing factor to develop BC with a life time risk of $10 \%$ in the general population (Easton 1997). Internationally $\mathrm{BC}$ is more frequent in developed countries due to the predominance of risk factors such as age and reproductive fashion, social economy, and diet (Parkin et al., 1997). It is the leading cause of cancer death in women with an estimate of 1.67 million ( $25 \%$ of all cancers) new cases diagnosed in 2012 (IARC 2012).

Data revealed a rapid upward trend in $\mathrm{BC}$ incidence in traditionally low frequency Asian countries as a consequence of altered living standards and adaptation of western lifestyles (Wilson et al., 2004). Over half of the breast cancer cases are estimated to occur in more industrialized countries, 788,200 (ASR=73.4/100,000) compared to less developed countries with 882,949 (ASR= $31.3 / 100,000)$. In general BC rate is higher in North America, Australia and Europe with mean average of 91.6, 86 and 84.8 per 100,000 respectively and moderate in South America (Mean= 51.6) and South Asia (Mean= 45.9) whereas Africa and central Asia show the least level of $\mathrm{BC}$ incidence with mean of 35.6 and 37.3 respectively
(IARC, 2012). The increase of BC incidence in western countries observed in late 1980s and 1990s is likely to be the result of changes in lifestyle and reproductive factors (Althuis et al., 1973-1997). In contrast, mortality rate of $\mathrm{BC}$ has been decreasing in North America and several European countries over the past two decades as a result of early detection and improved treatments (Jemal et al., 2010). Death rates, however, have been rising in many African and Asian countries with changes in reproductive pattern, physical activity and obesity (Parkin et al., 2005) (Figure 1). Breast cancer incidence is globally on the rise and it is swiftly striking less wealthy countries as a result of adoption of lifestyle changes that impact the prevalence of the disease (McTiernan 2003). Breast Cancer is the most common female cancer in the Middle East increasing up to 5\% each year (Kahan et al., 1997; Anderson 2006). The incidence of $\mathrm{BC}$ is roughly lower in Iranian population with 28.1 affected per 100,000 in comparison to the breast cancer in Asia and neighboring countries; 39.1 per 100,000 in Turkey and 50.3 per 100,000 in Pakistan (IARC 2012) (Table 1), however its rapid upward trend has become a national burden.

According to the CDC reports in Iran, breast cancer strikes women with a mean age of 48.8 years (Harirchi et al., 2004) where over $30 \%$ of malignancies occur below the age of 40 (Mousavi et al., 2006; National Cancer

${ }^{1}$ Genomic Research Center, ${ }^{2}$ Department of Medical Genetic, ${ }^{3}$ Department of Radiotherapy \& Oncology, ${ }^{4}$ Department of Surgery, Faculty of Medicine, Shahid Beheshti University of Medical Sciences, Tehran, Iran. *For correspondence: v.yassaee-grc@sbmu. ac.ir 
Registry report, 2004). Studies have shown that religious influence on lifestyle behaviors such as reproductive style, early age at first full-term pregnancy, higher number of births and more years of breast-feeding can extremely reduce the rate of female $\mathrm{BC}$ incidence (Merrill and Folsom, 2005; Sadjadi et al., 2009). Asians constitute $60 \%$ of the world population; hence, determination of risk of $\mathrm{BC}$ and mutation spectrum of the high penetrance genes can contribute to the better understanding and adoption of effective genetic testing (Kwong et al., 2015). The present retrospective cohort study aimed to identify the spectrum of BRCA mutations/variants in Iranian women with early onset $\mathrm{BC}$ during the past 15 years.

\section{Material \& Methods}

Subjects

Our previous study led to identification of BRCA germline mutations in 39 Iranian women with early onset breast cancer (Yassaee et al., 2002). Here we have expanded our investigations to obtain a BRCA data set of alterations in Iranian women with familial BC. During the past 15 years (1999-2014). 3,782 women who were diagnosed with breast and/or ovarian cancer (HBOC) referred to our center from hospitals throughout the country for consultation. Two hundred and fifty four patients who met the criteria were selected for BRCA analysis. The selection criteria included age $\leq 45$ with a history of at least two affected first degree relatives, bilateral $\mathrm{BC}$, male $\mathrm{BC}$ in the family and $\mathrm{BC}$ followed by ovarian cancer. The study was conducted in accordance to the NICE guidelines and was approved by ethical committee of deputy of research affairs of Shahid Beheshti University of Medical Sciences (SBUMS) (grant number 9293SBMU-931485). Following the declaration of Helsinki, whole blood samples were obtained from the subjects after informed and written consent was acquired. Genetic test results were provided to the patients upon request.

\section{Genetic Analysis}

Genomic DNA was prepared and BRCA analysis were performed for all coding exons and flanking intron and UTR sequences by single strand conformation polymorphism (SSCP), protein truncation test (PPT), multiplex ligation-dependent probe amplification (MLPA), and Sanger sequencing techniques. Results were analyzed by Finch TV 1.4 software. Primer sequences and PCR conditions are available on request.

\section{Results}

A total of 46 BRCA alterations were identified in this cohort study including 18 variants with unidentified clinical significance $(39.13 \%), 18$ missense mutations $(39.13 \%)$ and 7 indel mutations (15.21\%). Fifty BRCA negative patients were examined for LGR using MLPA whereby 3 of them showed a large deletion (Tables 2 and 3 ).
Table 1 . Incidence of Breast Cancer in the World in All Age Groups (GLOBOCAN 2012, IARC)

\begin{tabular}{|c|c|c|c|c|}
\hline Region & Country & Case & $\begin{array}{c}\text { ASI } \\
\text { rate per } \\
100,000\end{array}$ & Mean \\
\hline $\begin{array}{l}\text { North } \\
\text { America }\end{array}$ & USA & 256,222 & 91.6 & 91.6 \\
\hline \multirow{8}{*}{$\begin{array}{l}\text { South } \\
\text { America }\end{array}$} & Canada & 23,420 & 79.8 & \multirow[t]{6}{*}{51.6} \\
\hline & Mexico & 20,444 & 35.4 & \\
\hline & Colombia & 8,686 & 35.7 & \\
\hline & Peru & 3,952 & 28 & \\
\hline & Brazil & 67,316 & 59.5 & \\
\hline & Argentina & 19,386 & 71.2 & \\
\hline & UK & 52,399 & 95 & \multirow[t]{7}{*}{84.8} \\
\hline & Iceland & 225 & 96.3 & \\
\hline \multirow{11}{*}{ Europe } & Spain & 25,215 & 67.3 & \\
\hline & Sweden & 6,624 & 80.4 & \\
\hline & Finland & 4,477 & 89.4 & \\
\hline & Norway & 2,887 & 73.1 & \\
\hline & Germany & 71,623 & 91.6 & \\
\hline & Italy & 50,658 & 91.3 & \multirow{16}{*}{37.3} \\
\hline & France & 48,763 & 89.7 & \\
\hline & Denmark & 5,224 & 105 & \\
\hline & Belgium & 10,337 & 111.9 & \\
\hline & $\begin{array}{l}\text { The } \\
\text { Netherland }\end{array}$ & 13,895 & 99 & \\
\hline & Poland & 17,259 & 51.9 & \\
\hline \multirow{11}{*}{ Asia } & Belarus & 3,781 & 45.9 & \\
\hline & $\begin{array}{l}\text { Russian } \\
\text { Federation }\end{array}$ & 57,502 & 45.6 & \\
\hline & Kazakhstan & 6,252 & 63 & \\
\hline & Turkmenistan & 656 & 26.8 & \\
\hline & Turkey & 15,230 & 39.1 & \\
\hline & India & 144,937 & 25.8 & \\
\hline & China & 187,213 & 22.1 & \\
\hline & Iran & 9,795 & 28.1 & \\
\hline & Pakistan & 34,038 & 50.3 & \\
\hline & Afghanistan & 3,108 & 35 & \\
\hline & Saudi Arabia & 2,791 & 29.6 & 35.6 \\
\hline \multirow{4}{*}{ Africa } & Egypt & 18,660 & 49.5 & \\
\hline & Sudan & 3,439 & 27.8 & \\
\hline & Korea & 17,140 & 52.1 & 45.9 \\
\hline & Japan & 55,710 & 51.5 & \\
\hline \multirow[t]{3}{*}{ South Asia } & Philippine & 18,327 & 47 & \\
\hline & Malaysia & 5,410 & 38.7 & \\
\hline & Indonesia & 48,998 & 40.3 & \\
\hline Australia & Australia & 14,710 & 86 & 86 \\
\hline
\end{tabular}

ASI (ASR) indicates age standard rate per 100,000. Rates are standardized in accordance with the world population. Highlighted countries depict incidence of $\mathrm{BC}$ in comparison to Iran. 
Table 2. Germline Alterations in BRCA1/2 Genes

\begin{tabular}{|c|c|c|c|c|c|}
\hline Location & $\begin{array}{l}\text { cDNA Nomenclature } \\
\text { NM_007294.3 }\end{array}$ & Nucleotide Change & $\begin{array}{c}\text { AA change } \\
\text { NP_009225.1 }\end{array}$ & Variation class & $\begin{array}{r}\text { SNP } \\
(\mathrm{dbSNP})\end{array}$ \\
\hline \multirow[t]{2}{*}{ Exon 2} & c.66_67delAG & Del AG & p.Glu23Valfs*17 & FS & --- \\
\hline & c. $441+36 \_441+38 \mathrm{delCTT}$ & Del CTT & ---- & Intronic & rs $147,856,441$ \\
\hline \multirow{2}{*}{ Intron 7} & c. $441+52 \_441+63$ & & & & rs536,390,258 \\
\hline & delCTTTTTTTTTTT & Del CTTTTTTTTTTT & & & \\
\hline Exon 11 & c. $1067 \mathrm{~A}>\mathrm{G}$ & $\mathrm{A}>\mathrm{G}$ & p.Gln356Arg & MS & rs $1,799,950$ \\
\hline Intron 10 & c.671-248_671-246dup & Dup AGG & ---- & Intronic & --- \\
\hline Exon 11 & c. 1568 delT & Del T & p.Leu523Trpfs*9 & FS & --- \\
\hline Exon 11 & c.1684-1685 dup A & Dup A & p.Ile562Asnfs*9 & FS & \\
\hline Exon 11 & c. $2082 \mathrm{C}>\mathrm{T}$ & $\mathrm{C}>\mathrm{T}$ & p.Ser694= & Silent & rs $1,799,949$ \\
\hline Exon 11 & c.2216_2217delAA & Del AA & p.Lys739Serfs*3 & FS & --- \\
\hline Exon 11 & c. $2311 \mathrm{~T}>\mathrm{C}$ & $\mathrm{T}>\mathrm{C}$ & p.Leu771= & Silent & rs 16,940 \\
\hline Exon 11 & c. $2612 \mathrm{C}>\mathrm{T}$ & $\mathrm{C}>\mathrm{T}$ & p.Pro871Leu & MS & rs 799,917 \\
\hline Exon 11 & c.2649_2650insGGCA & Ins GGCA & p.Thr884Glyfs*20 & FS & ---- \\
\hline Exon 11 & c. $3113 \mathrm{~A}>\mathrm{G}$ & $\mathrm{A}>\mathrm{G}$ & p.Glu1038Gly & MS & rs 16,941 \\
\hline Exon 11 & c. $3548 \mathrm{~A}>\mathrm{G}$ & $A>G$ & p.Lys1183Arg & MS & rs 16,942 \\
\hline Exon 11 & c. $3748 \mathrm{G}>\mathrm{A}$ & $\mathrm{G}>\mathrm{A}$ & p.Glu1250Gln & MS & rs $28,897,686$ \\
\hline Intron 12 & c. $4097-141 \mathrm{~A}>\mathrm{C}$ & $\mathrm{A}>\mathrm{C}$ & ---- & Intronic & rs799,916 \\
\hline Exon 13 & c. $4308 \mathrm{~T}>\mathrm{C}$ & $\mathrm{T}>\mathrm{C}$ & p.Ser1436= & Silent & rs $1,060,915$ \\
\hline Exon 15 & c. $4609 \mathrm{C}>\mathrm{T}$ & $\mathrm{C}>\mathrm{T}$ & p.Gln1537X & NS & --- \\
\hline Exon 16 & c. $4837 \mathrm{~A}>\mathrm{G}$ & $A>G$ & p.Ser1613Gly & MS & rs1,799,966 \\
\hline Intron 17 & c. $5074+65 \mathrm{G}>\mathrm{A}$ & $\mathrm{G}>\mathrm{A}$ & ---- & Intronic & rs $8,176,235$ \\
\hline Intron 17 & c. $5074+284 \mathrm{C}>\mathrm{A}$ & $\mathrm{C}>\mathrm{A}$ & ---- & Intronic & rs $11,654,396$ \\
\hline Intron 18 & c. $5152+66 \mathrm{G}>\mathrm{A}$ & $\mathrm{G}>\mathrm{A}$ & ---- & Intronic & rs3,092,994 \\
\hline Intron 20 & $\begin{array}{c}\text { c. } 5277+59 \_5277+60 \\
\text { dup.GTATTCCACTCC }\end{array}$ & dup.GTATTCCACTCC & ---- & Intronic & rs $572,766,355$ \\
\hline
\end{tabular}

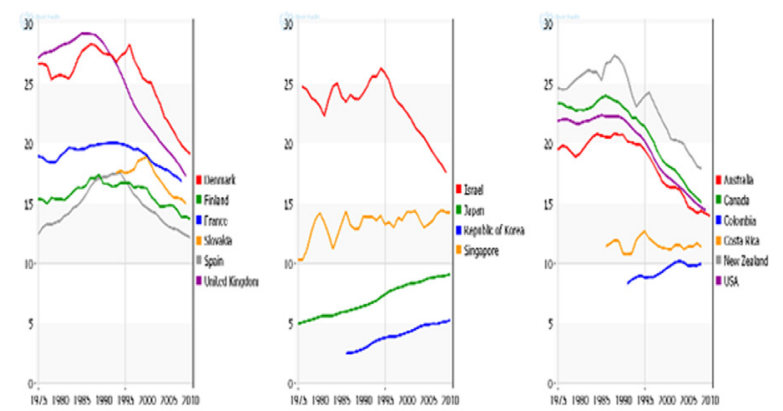

Figure 1. Trends in Female Breast Cancer Mortality Rates Per 100,000 (GLOBOCAN 2012, (IARC)

\section{Discussion}

Although the incidence of $\mathrm{BC}$ is lower in Iranian women compared to other Asian countries, based on data reported by the National Cancer Center, it is still a considerable health issue with an annual growth of $10 \%$. Incidence of breast cancer in Iran has risen since 1999 and currently it is the most adequate malignancy and the fifth most common form of death among Iranian women. In addition to living standards and environmental factors, genetic factors also significantly contribute to the odds of developing cancer. Women with family history of BC are at an estimated two fold risk of developing breast cancer whereby the risk progressively increases with the number of affected relatives. Majority of hereditary $\mathrm{BC}$ cases are associated to two faulty BRCA1 and BRCA2 genes with $55-65 \%$ and $45 \%$ risk respectively (Easton 2002). When a deleterious alteration in one of the genes is inherited, women will have increased risk of developing breast and ovarian cancer (Antoniou A et al., 2003). Deleterious mutations in BRCA1 confer $60-85 \%$ lifetime risk of $\mathrm{BC}$ and $46-60 \%$ risk of ovarian cancer (OC) while BRCA2 mutations account for 40-85\% lifetime risk of breast cancer (Lalloo and Evans, 2012). Thus far, over 500 types of various mutations have been defined in the Asian population with breast cancer (Kwong et al., 2015). The most prevalent mutations reported in the BRCA1 gene include c.68-69delAG, c.390C $>$ A, c.470-471delCT and c.981-982delAT and c.7480C $>$ T, c. $1399 \mathrm{~A}>\mathrm{T}$ and c.3744-3747delTGAG in the BRCA2 gene. The genetic aberrations have been widely observed in Chinese, Japanese, Pakistani and Korean populations (Kwong et al., 2015). Despite significant advances in screening techniques, breast cancer evades conventional therapies generating disease relapse and claiming the lives of women worldwide.

To evaluate the risk of breast and ovarian cancers in Iran, we analyzed BRCA genes in patients who 
Table 3. Germline Alterations in the BRCA2 Gene

\begin{tabular}{|c|c|c|c|c|c|c|}
\hline Location & $\begin{array}{l}\text { cDNA Nomenclature } \\
\text { NM_000059.3 }\end{array}$ & Nucleotide Change & $\begin{array}{l}\text { AA change } \\
\text { NP_000050.2 }\end{array}$ & $\begin{array}{l}\text { Variation } \\
\text { class }\end{array}$ & $\begin{array}{l}\text { SNP } \\
(\mathrm{dbSNP})\end{array}$ & $\begin{array}{l}\text { Biological } \\
\text { significance }\end{array}$ \\
\hline 5'UTR & c. $-26 \mathrm{G}>\mathrm{A}$ & $\mathrm{G}>\mathrm{A}$ & ---- & ---- & rs $1,799,943$ & 1-Neutral \\
\hline Exon 4 & c. $331 \mathrm{~A}>\mathrm{G}$ & $A>G$ & p.Asn111Asp & MS & ---- & 3-Neutral \\
\hline Intron 9 & c. $793+64$ delT & Del T & ---- & Intronic & --- & 3-Neutral \\
\hline Exon 10 & c. $865 \mathrm{~A}>\mathrm{C}$ & $\mathrm{A}>\mathrm{C}$ & p.Asn289Asp & MS & rs 766,173 & 1-Neutral \\
\hline Exon 10 & c. $1,114 \mathrm{~A}>\mathrm{C}$ & $\mathrm{A}>\mathrm{C}$ & p.Asn372His & MS & rs 144,848 & 1-Neutral \\
\hline Exon 11 & c. $2,971 \mathrm{~A}>\mathrm{G}$ & $A>G$ & p.Asn991Asp & MS & rs $1,799,944$ & Polymorphism \\
\hline Exon 11 & c. $3,396 \mathrm{~A}>\mathrm{G}$ & $\mathrm{A}>\mathrm{G}$ & p.Lys $1132=$ & Silent & rs $1,801,406$ & 1-Neutral \\
\hline Exon 11 & c. $3,807 \mathrm{~T}>\mathrm{C}$ & $\mathrm{T}>\mathrm{C}$ & p.Val1269= & Silent & rs543,304 & Polymorphism \\
\hline Exon 11 & c.3,751dup & Dup A & p.Thr1251Asnfs*14 & FS & ---- & NR (causative) \\
\hline Exon 11 & c. $5,081 \mathrm{G}>\mathrm{T}$ & $\mathrm{G}>\mathrm{T}$ & p.Arg1694Ile & MS & ---- & NR \\
\hline Exon 11 & c. $5,555 \mathrm{~T}>\mathrm{A}$ & $\mathrm{T}>\mathrm{A}$ & p.Val1852Asp & MS & rs $483,352,930$ & NR \\
\hline Exon 11 & c. $5,972 \mathrm{C}>\mathrm{T}$ & $\mathrm{C}>\mathrm{T}$ & p.Ala1991Val & MS & rs $80,358,829$ & NR \\
\hline Exon 11 & c.6,261_6,262insGT & Ins GT & p.Thr2088Valfs $* 32$ & FS & --- & NR (causative) \\
\hline Exon 11 & c. $6,513 \mathrm{G}>\mathrm{C}$ & $\mathrm{G}>\mathrm{C}$ & p.Val2171 = & Silent & rs 206,076 & 1-Neutral \\
\hline Intron 11 & $\begin{array}{l}\text { c. } 6,841+80 \_6841+83 \\
\text { delTTAA }\end{array}$ & Del TTAA & ---- & Intronic & rs $11,571,661$ & 3-UV \\
\hline Exon 14 & c. $7,242 \mathrm{~A}>\mathrm{G}$ & $\mathrm{A}>\mathrm{G}$ & p.Ser2414= & Silent & rs $1,799,955$ & 1-Neutral \\
\hline Exon 14 & c. $7,397 \mathrm{C}>\mathrm{T}$ & $\mathrm{C}>\mathrm{T}$ & p.Ala2466Val & MS & rs 169,547 & 1-Neutral \\
\hline Intron 16 & c. $7,806-14 \mathrm{~T}>\mathrm{C}$ & $\mathrm{T}>\mathrm{C}$ & ---- & Intronic & rs $9,534,262$ & 1-Neutral \\
\hline Exon 18 & c. $8,117 \mathrm{~A}>\mathrm{G}$ & $\mathrm{A}>\mathrm{G}$ & p.Asn2706Ser & MS & ---- = & 3-UV \\
\hline Exon 20 & c. $8,490 \mathrm{G}>\mathrm{A}$ & $\mathrm{G}>\mathrm{A}$ & p.Trp2830X & NS & ---- & NR (causative) \\
\hline Exon 22 & c. $8,851 \mathrm{G}>\mathrm{A}$ & $\mathrm{G}>\mathrm{A}$ & p.Ala2951Thr & MS & rs $11,571,769$ & 1-Neutral \\
\hline Exon 23 & c. $9,266 \mathrm{C}>\mathrm{T}$ & $\mathrm{C}>\mathrm{T}$ & p.Pro3089Leu & MS & --- & NR \\
\hline Exon 27 & c. $9,827 \mathrm{G}>\mathrm{A}$ & $\mathrm{G}>\mathrm{A}$ & p.Arg3276Lys & MS & --- & NR \\
\hline Exon 27 & c. $9,976 \mathrm{~A}>\mathrm{T}$ & $\mathrm{A}>\mathrm{T}$ & p.Lys3326X & NS & ---- & NR (causative) \\
\hline
\end{tabular}

MS, MissenseMutation; NS, NonsenseMutation;FS,Frameshiftmutation; NR, NotReportedinUMD; ClassificationofBRCA1/2alterations based on formerly UMD mutation database; Class 1, Neutral, neutral polymorphism; Class 2, Likely neutral, Contradictory neutral/ UV; Class3,Unknown/unclassifiedvariant(UV);Class4:Likelydeleterious, Contradictorydeleterious/UV;Class5:Deleteriousmutation

referred to our clinic. The alterations consisting indel/ duplication lead to large genomic rearrangement (LGR) undetectable by common screening assays. Therefore, MLPA was implemented as a robust and sensitive method for detection of the LGRs in patients negative for BRCA mutations asserted by Sanger sequencing. Among 254 patients who met the increased risk criteria, mutations in BRCA $1 / 2$ were detected in $18 \%$ of the patients comprising $39.13 \%$ missense, $15.21 \%$ indel and $39.13 \%$ unknown clinical significant alterations (Table $2 \mathrm{a}, \mathrm{b}$ ). We have also demonstrated that LGRs encompass a significant fraction of $6 \%$ of all substantial mutations in the BRCA1 gene (Yassaee et al., 2013). These findings suggest that early onset and high risk clinical history were efficient criteria for investigation of patients possibly harbor faulty genes. Germline mutations in BRCA1/2 are significant prognosticators of breast and ovarian cancers presenting variable prevalence and penetrance among ethnic groups (Fackenthal and Olopade, 2007). Mutations in the BRCA genes are expected to increase the risk of breast cancer in women. However, BRCA negative women from BRCA families are at higher risk of developing breast cancer than the general population as a result of SNP variations that are associated with breast cancer (Evans et al., 2013). It is noteworthy to accentuate that mere dependence on BRCA mutations is a poor judgment of a woman's future cancer risk while she may still have a significant risk of developing a new primary cancer (Pohlreich et al., 2005). Risk assessment of BC for family members, in addition to a three generation pedigree also confides to the integration of new genomic techniques and prognostic profiles for early detection and accurate diagnosis of BC in terms of suitable treatment and better quality of life. Management of hereditary/familial BC varies from sporadic tumors. In 2004, UK National Institute for Clinical Excellence (NICE) issued a protocol for managing hereditary/familial breast cancer which aims to classify women on the basis of high, moderate and average risk of BC (McIntosh et al., 2004). The amalgamation of clinical features and molecular techniques has led to the stratification of breast cancer types. These approaches can complement the present diagnostic tests and aid in better understanding of molecular basis of BC.

In summary, incidence of $\mathrm{BC}$ is globally divergent among countries and various ethnic groups. The present study represents the largest BRCA1/2 mutation analysis 
in Iranian women with early onset BC. The targeted patient cohorts comprise probabilities of carrying a wide range of mutations. We documented a variety of alteration demonstrating the framework for assessing the overall importance of BRCA1/2 analysis. Our findings not only provide a data set of BRCA alterations in high risk Iranian families with breast cancer, but also update and contribute to the present $\mathrm{BC}$ data set reported by Kwong et al in 2015. The overall knowledge of BRCA1/2 mutations will assist in genetic counseling and ultimately in the disease management of patients who need them the most.

\section{Acknowledgements}

We thank the patients and their families for their cooperation and participation. The study was funded by Genomic Research Center, Shahid Beheshti University of Medical Sciences (SBUMS), Tehran-Iran, grant number (9293SBMU 931485). All procedures performed in studies involving human participants were in accordance with the ethical standards of the institutional and/or national research committee and with the 1964 Helsinki declaration and its later amendments or comparable ethical standards. Authors declare no conflict of interest

\section{References}

Althuis MD, Dozier JM, Anderson WF, et al (2005). Global trends in breast cancer incidence and mortality 1973-1997. Int $J$ Epidemiol, 34, 405-12.

Anderson BO (2006). Breast healthcare and cancer control in limited-resource countries: a framework for change. Nat Clin Pract Oncol, 3, 4-5.

Antoniou A, Pharoah PD, Narod S, et al (2003). Average risks of breast and ovarian cancer associated with BRCA1 or BRCA2 mutations detected in case Series unselected for family history: a combined analysis of 22 studies. Am J Hum Genet, 72, 1117-30.

DF Easton (2002). Familial risks of breast cancer. Breast Cancer Res, 4, 179-81.

Easton D (1997) Breast cancer genes what are the real risks. Nat Genet, 16, 210-1.

Evans DG, Ingham SL, Buchan I, et al (2013). Increased rate of phenocopies in all age groups in BRCA1/BRCA2 mutation kindred, but increased prospective breast cancer risk is confined to BRCA2 mutation carriers. Cancer Epidemiol Biomarkers Prev, 22, 2269-76.

Fackenthal JD, Olopade OI (2007). Breast cancer risk associated with BRCA1 and BRCA2 in diverse populations. Nat Rev Cancer, 7, 937-48.

Harirchi I, Karbakhsh M, Kashefi A, et al (2004). Breast cancer in Iran: results of a multi-center study. Asian Pac J Cancer Prev, 5, 24-7.

Jemal A, Center MM, DeSantis C, et al (2010). Global patterns of cancer incidence and mortality rates and trends. Cancer Epidemiol Biomarkers Prev, 19, 1893-7.

Kahan E, Ibrahim AS, El Najjar K, et al (1997). Cancer patterns in the Middle East special report from the Middle East Cancer Society. Acta Oncol, 36, 631-6.

Kwong A, Shin VY, Ho JC, Kang E, et al (2015). Comprehensive spectrum of BRCA1 and BRCA2 deleterious mutations in breast cancer in Asian countries. J Med Genet, 53, 15-23.

Lalloo F, Evans DG (2012). Familial breast cancer. Clin Genet,
82, 105-14.

McIntosh A, Shaw C, Evans G et al (2004). Clinical guidelines and evidence review for the classification and care of women at risk of familial breast cancer. London: National collaborating center for primary care/University of Sheffield (www. nice.org.uk/CG041, updated 2006).

McTiernan A (2003). Behavioral risk factors in breast cancer: can risk be modified?. Oncologist, 8, 326-34.

Merrill RM, Folsom JA (2005). Female breast cancer incidence and survival in Utah according to religious preference, 1985-1999. BMC Cancer, 5, 49.

Mousavi SM, Mohaghegghi MA, Mousavi-Jerrahi A, et al (2006). Burden of breast cancer in Iran: a study of the Tehran population based cancer registry. Asian Pac J Cancer Prev, 7, 571-4.

National Cancer Registry report, (2004). Tehran, Cancer Administration, Non-communicable Diseases Sector, Iranian Center for Diseases Control and Prevention, 2005 [in Farsi].

Parkin DM, Whelan S, Ferlay J, et al (2005). Cancer Incidence in Five Continents. Vol I to VIII. Cancer base No. 7. Lyon: IARC Press.

Parkin DM, Whelan SL, Ferlay J, et al (1997). Cancer incidence in five continents. vol. VII. Lyon. IARC Scientific Publications no. 143.

Pohlreich P, Zikan M, Stribrna J, et al (2005). High proportion of recurrent germline mutations in the BRCA1 gene in breast and ovarian cancer patients from the Prague area. Breast Cancer Res, 7, 728-36.

Sadjadi A, Nouraie M, Ghorbani A, et al (2009). Epidemiology of breast cancer in the Islamic Republic of Iran: first results from a population-based cancer registry. East Mediterr Health $J, 15,1426-31$.

Wilson CM, Tobin S, Young RC (2004). The exploding worldwide cancer burden: the impact of cancer on women. Int J Gynecol Cancer, 14, 1-11.

Yassaee VR, Emamalizadeh B, Omrani MD (2013). Screening for genomic rearrangements at BRCA1 locus in Iranian women with breast cancer using multiplex ligation-dependent probe amplification. J Genet, 92, 131-4.

Yassaee VR, Zeinali S, Harirchi I, et al (2002). Novel mutations in the BRCA1 and BRCA2 genes in Iranian women with early-onset breast cancer. Breast Cancer Res, 4, 6-15. 